\title{
Autoreactive T cells in type 1 diabetes
}

\author{
Alberto Pugliese \\ Diabetes Research Institute, Department of Medicine, Division of Endocrinology, Diabetes, and Metabolism, Department of Microbiology and Immunology, Miller School of Medicine, \\ University of Miami, Miami, Florida, USA.
}

\begin{abstract}
Type 1 diabetes (T1D) is a chronic autoimmune disease that causes severe loss of pancreatic $\beta$ cells. Autoreactive T cells are key mediators of $\beta$ cell destruction. Studies of organ donors with T1D that have examined T cells in pancreas, the diabetogenic insulitis lesion, and lymphoid tissues have revealed a broad repertoire of target antigens and T cell receptor (TCR) usage, with initial evidence of public TCR sequences that are shared by individuals with T1D. Neoepitopes derived from post-translational modifications of native antigens are emerging as novel targets that are more likely to evade self-tolerance. Further studies will determine whether $\mathrm{T}$ cell responses to neoepitopes are major disease drivers that could impact prediction, prevention, and therapy. This Review provides an overview of recent progress in our knowledge of autoreactive T cells that has emerged from experimental and clinical research as well as pathology investigations.
\end{abstract}

\section{Introduction}

Type 1 diabetes (T1D) is a chronic autoimmune disease resulting in severe loss of pancreatic $\beta$ cells (1) due to the targeting of islet cell autoantigens. Autoantibody and T cell responses to autoantigens are detected in at-risk individuals during the asymptomatic period preceding T1D diagnosis and at clinical onset. Autoantibodies are robust predictive and diagnostic biomarkers (2); autoreactive $\mathrm{T}$ cells are considered the main effectors of $\beta$ cell destruction. Accordingly, $50 \%-60 \%$ of the genetic risk for T1D derives from HLA alleles encoding molecules involved in the presentation of antigen peptides to T cells (3). An individual's HLA variants influence peptide binding and signal transduction after $\mathrm{T}$ cell receptor (TCR) engagement. These influences on antigen presentation are key during thymic selection processes and peripheral activation of the immune response.

Strong predisposition for T1D derives from selected HLA class II (HLA-II) haplotypes, especially $H L A-D R B 1^{*} 04$ (DR4), DQA1*O3: 01-DQB1 ${ }^{*} 03: 02$ (DQ8), HLA-DRB1*03:01 (DR3), and DQA1*05: O1-DQB1 ${ }^{*} 02: 01$ (DQ2). Approximately $80 \%-90 \%$ of patients carry at least one high-risk haplotype, and 30\%-50\% have both (4). The heterozygous genotype confers the strongest predisposition due to the formation of a trans-complementing HLA-DQ heterodimer, consisting of the DQ2 $\alpha$-chain $\left(D Q A 1^{*} 05: 01\right)$ and the DQ8 $\beta$-chain $\left(D Q B 1^{*} 03: 02\right)$, which effectively presents autoantigen epitopes to T cells (5). The HLA-DRB1 chain is also involved in the presentation of diabetogenic epitopes, but $D R B 1^{*} O 4$ variants differ in their disease association even when in cis with the high-risk $D Q A 1^{*} 03: 01-D Q B 1^{*} 03: 02(4)$. Selected HLA-I variants such as HLA-A2, HLA-A24, HLA-B39, HLA-B57, and HLA-B18 contribute to T1D risk $(3,6)$. HLA-A2 is also common in the general population, being present in about $50 \%$ of individuals of European descent. Most studies of autoreactive CD4 ${ }^{+}$and $\mathrm{CD} 8^{+}$ $\mathrm{T}$ cell responses in T1D have focused on those restricted by these

Conflict of interest: The author has declared that no conflict of interest exists Reference information: J Clin Invest. 2017;127(8):2881-2891.

https://doi.org/10.1172/JCI94549.
HLA types (7). The ability to detect and phenotype autoreactive T cells in circulation, where they are present at extremely low frequencies, has greatly improved. For example, HLA-II tetramers or HLA-I multimers/monomers allow measurement of autoreactive $\mathrm{T}$ cells in the circulation ex vivo, without in vitro amplification that might alter phenotypic features (8-10).

This Review integrates experimental, human pathology, and clinical research studies and identifies key outstanding questions related to autoreactive T cells in T1D.

\section{T cells in the T1D pancreas}

For decades, pathology studies relied on sporadic access to T1D pancreata (11). Early efforts to recover T1D pancreata include collecting autopsy specimens from recently diagnosed patients in the United Kingdom (12) and limited percutaneous biopsies from living patients in Japan (13). In the last decade, the DiViD study from Norway (14) obtained laparoscopic biopsies from 6 adult patients near diagnosis, and the JDRF Network for Pancreatic Organ Donors with Diabetes (nPOD) in the USA recovers pancreatic and other tissues from T1D donors to support diabetes researchers worldwide and engage investigators in collaborative studies (15). nPOD enables examination of T1D pancreata from donors with a wide range of disease durations (16).

The pathologic hallmark of T1D is insulitis, an inflammatory lesion of the islet associated with $\beta$ cell loss (17-19). Inflammatory cells are observed in the islet periphery (peri-insulitis) or within the islet parenchyma. Peri-insulitis is the predominant lesion in the human pancreas $(16,20)$ and is less severe than insulitis in the NOD mouse model $(16,20,21)$. Insulitis is defined by at least 15 $\mathrm{CD} 45^{+}$cells/islet present in three or more islets, with concomitant evidence of insulin-negative islets, dubbed pseudo-atrophic islets (18). Only $10 \%-30 \%$ of islets show insulitis at any time, even when tissue is obtained at diagnosis, including in nPOD and DiViD specimens $(14,16,17,21)$. George Eisenbarth dubbed the lobular and patchy distribution of insulitis "vitiligo of the pancreas" in his Banting lecture (22). The lesion typically affects insulin-positive islets, suggesting that $\mathrm{T}$ cells leave islets after destroying $\beta$ cells. 
Insulitis and $\mathrm{T}$ cell-mediated $\beta$ cell destruction

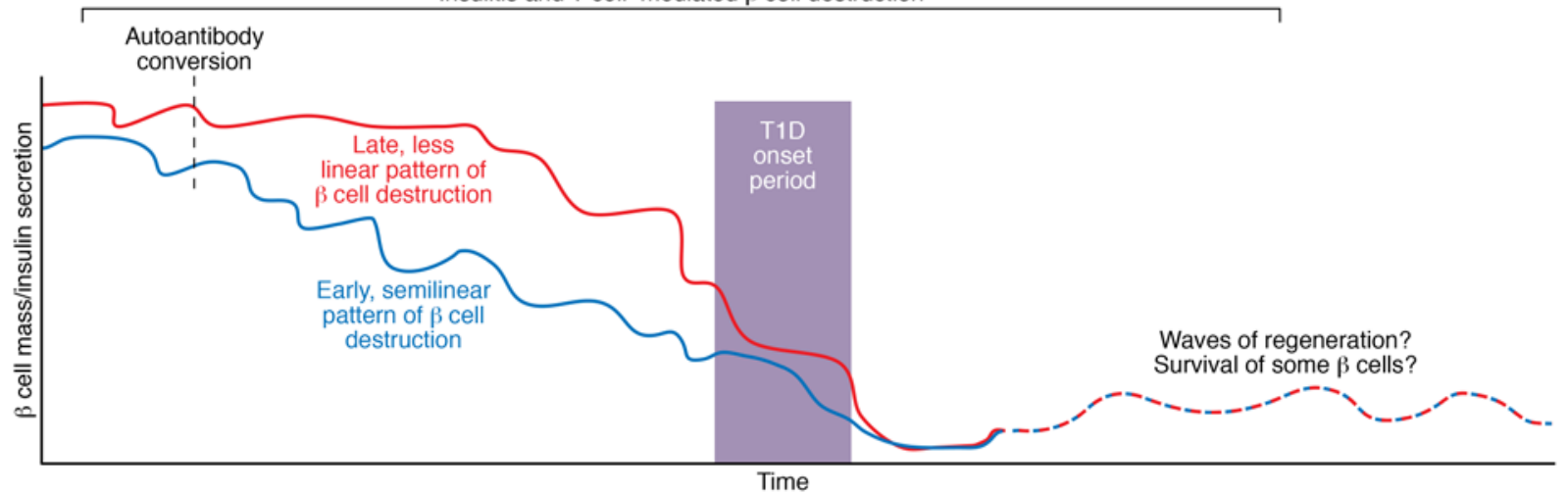

Figure 1. The natural history of islet autoimmunity. To illustrate the chronic nature and heterogeneity of islet autoimmunity and highlight critical gaps in knowledge, this figure depicts two hypothetical patterns of T cell-mediated $\beta$ cell destruction and loss of insulin secretion: early triggering of insulitis and semi-linear $\beta$ cell destruction (blue line); or late start of the autoimmune $\beta$ cell destruction, closer to clinical diagnosis (red line). This is a simplified schematic representation: loss of $\beta$ cell mass and insulin secretion may not always correlate and may vary based on the relative importance of autoimmune destruction and $\beta$ cell dysfunction during disease progression in a given patient. Seroconversion for T1D-associated autoantibodies to native antigens is considered the earliest step in the triggering of islet autoimmunity; it occurs in early life in children at genetic risk of T1D, but it may occur later in life in many individuals. As only a minority of islets are affected at any given time, the process proceeds asynchronously. Residual $\beta$ cell mass at onset may be a function of the severity of autoimmune destruction and initial mass, which are impacted by age. It is often incomplete at diagnosis, but it continues afterward, sometimes for years. Low levels of insulin secretion are detected in many patients even decades after diagnosis: some $\beta$ cell regeneration occurs after diagnosis, and it has been hypothesized that regeneration may occur during the preclinical stage. Critical questions remain unanswered: To what extent and when does the detection of humoral and cellular responses in the circulation reflect insulitis and $\beta$ cell destruction, and which responses are relevant? At what time are insulitis and $\beta$ cell destruction triggered during the progression of islet autoimmunity? Is there a preferred order for autoantibody and T cell responses to native antigens and neoepitopes, and what are their relative roles in insulitis, $\beta$ cell destruction, and disease onset (trigger/driver responses versus secondary responses)?

Eventually, most islets become pseudo-atrophic remnants of islet autoimmunity. In studies of 80 nPOD T1D donors $(16,23), 17$ donors with up to 12 years of disease duration exhibited insulitis; thus, islet autoimmunity may persist for years after diagnosis. Residual $\beta$ cells were present in all T1D donors with insulitis, and their $\beta$ cell mass was higher than in T1D donors without insulitis. T1D patients with more than 50 years of diabetes and residual insulin secretion also displayed insulitis and residual $\beta$ cells (24).

$\mathrm{CD}^{+} \mathrm{T}$ cells are the predominant $\mathrm{T}$ cell population and most abundant inflammatory cell type in insulitis. Using HLA multimers, investigators demonstrated the antigen specificity of autoreactive $\mathrm{CD} 8^{+} \mathrm{T}$ cells in insulitis lesions of nPOD T1D donors (23). The infiltrating $\mathrm{CD}^{+} \mathrm{T}$ cells' antigen repertoire increased in diversity with longer disease duration (23). Thus, antigen/epitope spreading occurs or continues after diagnosis (Figure 1).

Hyperexpression of HLA-I molecules by endocrine cells in insulin-containing islets is another key feature of the T1D pancreas (25). This observation was confirmed with various methodologies in multiple patient cohorts (26) (Figure 2). Hyperexpression of HLA-I molecules helps explain the predominance of $\mathrm{CD}^{+} \mathrm{T}$ cells in insulitis. Earlier studies also reported aberrant expression of HLA-II molecules by $\beta$ cells in 22 of 26 and 6 of 12 pancreata from patients with recent-onset and long-standing disease, respectively $(25,27$, 28). Expression of HLA-I/II molecules may be triggered by viruses linked to T1D $(29,30)$. Inflammatory cytokines (IFN- $\gamma$ plus TNF- $\alpha$ or lymphotoxin) induce HLA-I/II molecules on $\beta$ cells in vitro (31, 32). The significance of HLA-II expression by cells was investigated using transgenic expression of MHC class II (MHC-II) molecules in $\beta$ cells, which did not drive immune infiltration of mouse islets (3335). However, these studies were not conducted in diabetes-prone mice, and the role of MHC-II expression in the presence of defec- tive self-tolerance to $\beta$ cell antigens and predisposing MHC variants remains controversial. Thus, HLA-II expression by $\beta$ cells in the T1D pancreas should be reassessed with modern methodology and experimental models given the hypothetical implication that $\beta$ cells may directly present self-antigens to autoreactive $\mathrm{CD} 4^{+} \mathrm{T}$ cells (Figure 3) (36).

\section{T cells in the prediabetic pancreas}

Clinical onset of T1D is preceded by an asymptomatic period lasting months to years during which autoimmunity causes progressive $\beta$ cell destruction (Figure 1). Autoantibody screening identifies individuals at risk for T1D among patients' relatives; those with a single autoantibody have low risk, while about $40 \%-80 \%$ of relatives with multiple autoantibodies develop T1D within 5-10 years, respectively (2). However, the extent to which humoral and cellular autoimmune responses in blood reflect ongoing pancreas pathology during the prediabetic period are unknown, as is the relationship of autoantibody positivity with insulitis and the features of islet-infiltrating T cells. Despite progress in identifying autoantibodypositive non-diabetic donors $(15,37-39)$, recoveries have been too few; we advocate that pancreata from these rare donors should be allocated to research rather than transplant whenever possible (40).

The limited data available from nPOD (16) and European studies $(41,42)$ suggest that insulitis is found only in donors with high-risk HLA types and multiple autoantibodies. Higher T1D risk associated with multiple autoantibodies may reflect ongoing insulitis, and low risk associated with a single autoantibody appears consistent with lack of insulitis in pancreata of organ donors with a single autoantibody (mostly against GAD65). Since these donors are identified in the general population and many lack T1Dpredisposing HLA types $(16,43)$, only some may be representa- 


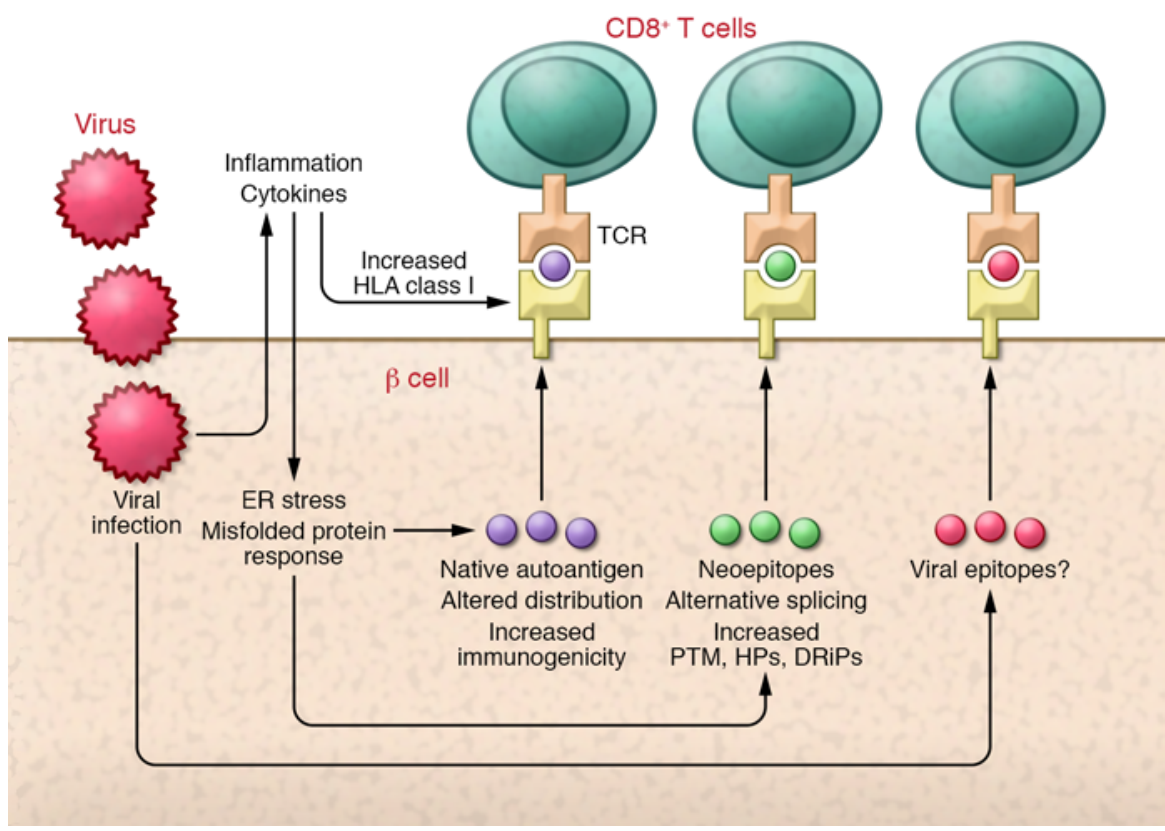

Figure 2. CD8 $\boldsymbol{T}$ cell responses to pancreatic $\beta$ cells. Schematic representation of major autoantigen classes that may be targeted by $\mathrm{CD} 8^{+} \mathrm{T}$ cells, the predominant immune cell type in the insulitis. As described in the main text, these may include native antigens and neoepitopes. The generation of these epitopes may be promoted by $\beta$ cell inflammation and stress. Insulitis is often associated with an interferon response with hyperexpression of HLA class I molecules, which may be induced by viral infections. Hyperexpression of HLA class I molecules facilitates presentation of autoantigen epitopes to $C D 8^{+} T$ cells. Whether islet-infiltrating $C D 8^{+} \mathrm{T}$ cells also target viral epitopes remains to be investigated efflux transporter ZNT8 (7, 81-85), chromogranin $(86,87)$, islet-amyloid polypeptide (IAPP) (8), and more. Many are present in secretory granules, and some are unique to $\beta$ cells (insulin, IGRP, ZNT8), while some are expressed in other cells and tissues, including neuroendocrine cells (GAD65, IA-2) $(88,89)$.

Autoimmune responses to islet cell self-molecules evidence a specific loss of immunological self-tolerance. Most self-molecules, including those with tissuerestricted expression, are expressed in the thymus early in life to establish central tolerance (90). Yet several mechanisms may determine suboptimal thymic expression and, in turn, imperfect self-tolerance. For T1D autoantigens, allelic variation and epigenetic regulation affect the selection and levels of self-epitopes presented to developing $\mathrm{T}$ cells during thymic selection. A polymorphic variable nucleotide tandem repeat (VNTR) sequence at the $5^{\prime}$ of the insulin gene influences thymic expression of insulin, and alleles that confer resistance to T1D are associated with higher insulin thymic transcription than predisposing variants $(91,92)$. Epigenetic regulation may suppress thymic transcription of a parental copy of the insu-

tive of pre-diabetes. However, abnormalities are reported in the pancreas of donors with single autoantibodies (15): accumulation of proinsulin-containing vesicles in $\beta$ cells observed in nPOD organ donors with single and multiple autoantibodies may reflect impaired proinsulin conversion, disrupted vesicular trafficking, and possibly increased metabolic requirements and stress. Consistent with the increases in size and number of $\beta$ cells/islet observed in autoantibody-positive donors (44), there is no evidence of reduced $\beta$ cell mass in independent analyses of autoantibodypositive nPOD donors $(44,45)$. Based on these findings, Figure 1 illustrates two theoretical patterns of $\beta$ cell destruction: insulitis may begin early, with destruction proceeding in a semi-linear fashion; or insulitis and $\beta$ cell destruction may occur closer to diagnosis. The latter fits the observations that (i) the proportion of infiltrated islets is modest near diagnosis, and insulitis is only present in non-diabetic donors with multiple autoantibodies $(16,21,23)$; (ii) $\beta$ cell loss near diagnosis is partial in many patients $(16,21,23)$, and no appreciable reduction in $\beta$ cell mass has been reported in autoantibody-positive donors (44, 45); and (iii) impaired glucose metabolism, abnormalities of insulin secretion $(46,47)$ and insulin sensitivity (48), and increased $\beta$ cell death (49) usually manifest shortly before diagnosis in longitudinal studies of at-risk relatives.

\section{Loss of immunological tolerance to $\beta$ cells}

Several islet cell molecules were identified as targets of autoimmunity in T1D, including native proteins and epitopes of proinsulin (9, 50-63), GAD65 (64-72), tyrosine phosphatase-like insulinomaassociated antigen 2 (IA-2) (67, 73-75), islet-specific glucose-6-phosphatase catalytic subunit-related protein (IGRP) $(76-80)$, the cation lin gene, especially for T1D-protective alleles associated with higher transcription (91-93). These mechanisms may allow autoreactive $\mathrm{T}$ cells to escape thymic selection, as reported for insulin in mouse models (94-98) and patients $(99,100)$.

T1D-predisposing HLA molecules may contribute to suboptimal thymic presentation of autoantigens. Weak interactions between a preproinsulin peptide and HLA-A2 lead to suboptimal presentation to the TCR of responding $\mathrm{CD}^{+} \mathrm{T}$ cells (101), which may more easily survive thymic selection. Of note, HLA-A2 is found also in about $50 \%$ of the general European-descent population; the often-reported detection of circulating autoreactive $\mathrm{T}$ cells in healthy individuals (102) may derive from negative selection processes that are inherently imperfect for islet cell selfmolecules. However, autoreactive $\mathrm{T}$ cells in T1D patients are reportedly enriched in memory cells versus a naive phenotype in healthy subjects $(103,104)$. The positive effects of treatment with an anti-memory cell agent in patients with recently diagnosed T1D supports the importance of memory autoreactive T cells in this disease $(105,106)$. Memory autoreactive T cells were linked to T1D recurrence in transplanted patients, both in islet $(107,108)$ and pancreas transplantation (109), despite immunosuppression.

Autoreactive T cells exhibit proinflammatory cytokine profiles in T1D patients and regulatory profiles in healthy subjects $(85,110$, 111). T1D patients exhibit defects in peripheral tolerance, including impaired Treg function $(112,113)$ and effector T cell (Teff) resistance to Treg suppression (114). Many T1D risk genes predispose to impaired immune regulation (115); the best studied are PTPN22 (encoding protein tyrosine phosphatase, non-receptor type 22), CTLA4 (encoding cytotoxic T lymphocyte-associated protein 4), 

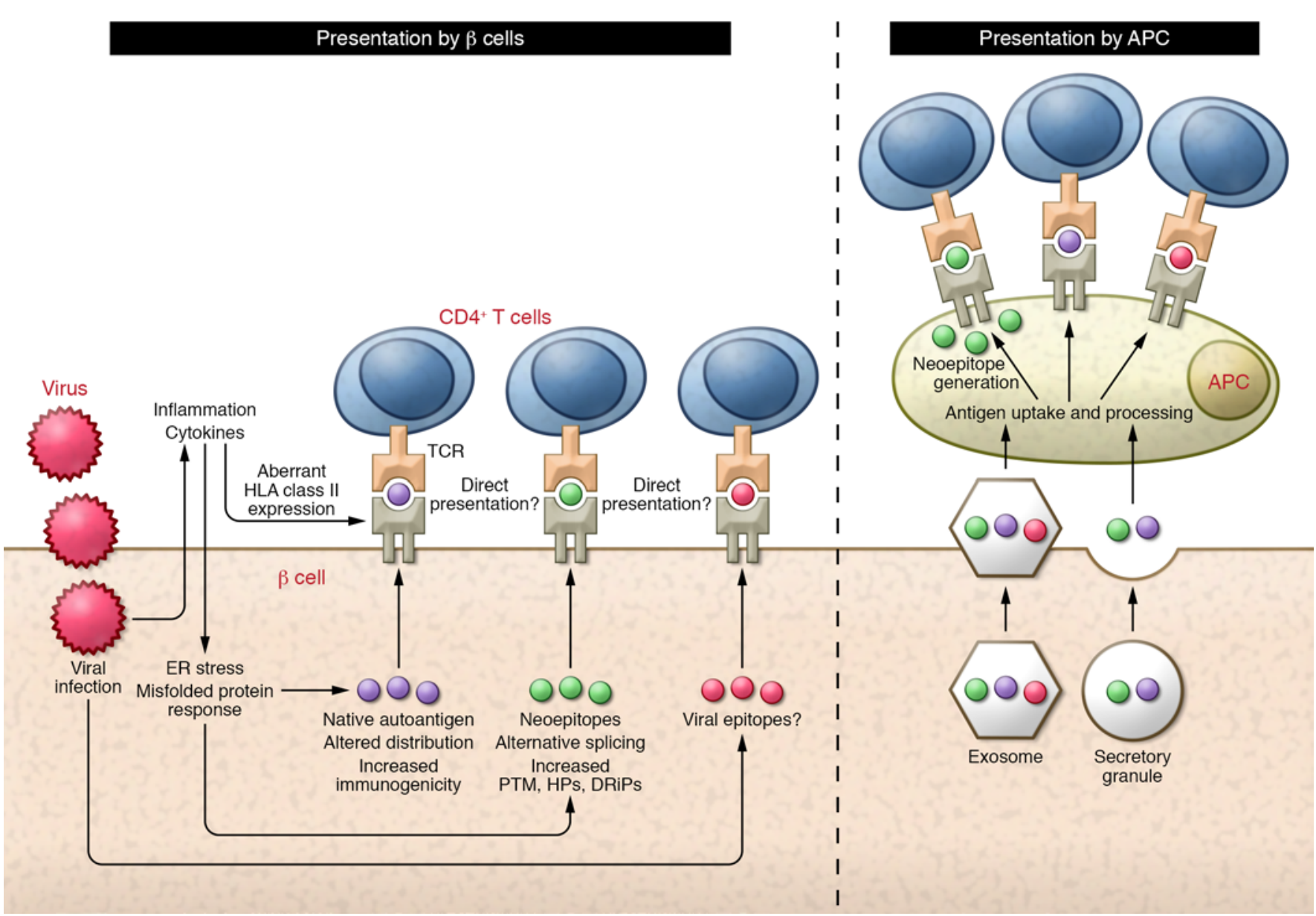

Figure 3. CD4 ${ }^{+}$T cell responses to pancreatic $\beta$ cells. Schematic representation of major autoantigen classes that may be targeted by CD4 ${ }^{+} \mathrm{T}$ cells. Similar to $C D 8^{+} T$ cells, these may include native antigens and neoepitopes, which may be formed under conditions of $\beta$ cell inflammation and stress. $\beta$ Cells can produce several neoepitopes: for example, peptides originating from alternative splicing, insulin hybrid peptides (HP), and DRiP insulin peptides are reportedly produced in $\beta$ cells (for DRiPs, the evidence is from studies of cell lines). Many autoantigens are secretory granule proteins, which may be released by $\beta$ cells and acquired by APCs. Exosomes released by $\beta$ cells also contain autoantigens. CD4 ${ }^{+} T$ cells may react with antigens captured, processed, and presented by APCs in the pancreatic lymph node and in the islets. The B:9-23 epitope is produced in the secretory granules, captured, and presented by APCs, at least in the NOD mouse. The generation of neoepitopes in $\beta$ cells further raises the question of whether the previously reported aberrant expression of HLA class II molecules by $\beta$ cells might allow $\mathrm{CD}^{+}$T cells to recognize antigens on their surface directly.

and IL2RA (encoding the IL-2 receptor $\alpha$-chain, IL-2R $\alpha$ ), which control TCR signaling, inhibition of $\mathrm{T}$ lymphocyte responses, and Treg development and function $(116,117)$, respectively.

Environmental exposures may promote loss of tolerance. Along with their epidemiological associations $(29,30)$, enterovirus infections of $\beta$ cells impair insulin secretion (118), alter mRNA/miRNA expression $(119,120)$, and induce interferon responses $(121,122)$ that promote $\beta$ cell stress, dysfunction, and apoptosis (123). Enteroviruses may also trigger autoimmunity via presentation of self-molecules in an inflammatory context (bystander activation) (124) and/or by molecular mimicry (125-127). Cross-reactivities with viral proteins were reported for autoantibody (128-134) and $\mathrm{T}$ cell responses (73, $132,135-144)$ with GAD65, IA-2, and insulin autoantigens. $\beta$ Cell inflammation and ER stress promote $\beta$ cell dysfunction and immunogenicity, and protein misfolding is associated with abnormal autoantigen presentation (145-147). Cytokine-induced ER stress enhances $\beta$ cell release of exosomes loaded with autoantigens and immunostimulatory chaperones, which are taken up by antigenpresenting cells (APCs) and may be presented to T cells (Figure 3)
(148). Dendritic cells' efficiency at cross-presentation is important for self-tolerance (149-151) and viral responses (152) but is also linked to T1D in NOD mice (153-155). In the NOD mouse, self-antigen cross-presentation to $\mathrm{CD} 8^{+} \mathrm{T}$ cells is also mediated by $\mathrm{B}$ lymphocytes and promotes disease progression (156).

\section{Modified T cell autoantigens (neoepitopes)}

Increasing evidence suggests that islet autoimmunity also targets neoepitopes expressed by the target cells, which may not be available for negative thymic selection. Differential expression of $I A-2$ and IGRP mRNAs in thymus and pancreas $(157,158)$ may promote autoimmunity, as the immune system may not be tolerant to alternatively spliced variants expressed in pancreas but not thymus (159). Many autoantigens in autoimmune disease are post-translationally modified (PTM) (160). Inflammation and stress are likely factors in the generation of PTM antigens, which derive from both normal and abnormal processes in cells. Predisposing HLA types are critical for the presentation of these epitopes to T cells $(161,162)$. Below, the major neoepitope classes associated with T1D are described. 
Neoepitopes generated by PTM. A PTM epitope exists in the insulin A chain (A1-A13): $\mathrm{T}$ cell recognition requires oxidized cysteine residues at $\mathrm{A} 6$ and $\mathrm{A} 7$, with the formation of a vicinal disulfide bond between them (60). Other forms of PTM include citrullination (163) and transglutamination, which enhance GAD65 peptide binding to HLA-DRB1 ${ }^{*}$ 4:01 and modulate recognition by modifying amino acids at TCR contact positions (164). Memory T cells reacting with these PTM epitopes were detected in blood at a higher frequency in T1D patients than controls. The same T cells had weak or no reactivity toward the native peptides. Tissue transglutaminase mediates the deamidation reaction and generates PTM antigens in celiac disease, which shares HLA-II susceptibility with T1D (111). The HLA-DQ trans-dimer formed in DQ8/DQ2 heterozygotes exhibits binding preference for negatively charged peptides generated by deamidation. Van Lummel at al. (111) identified CD $4^{+}$ $T$ cells against proinsulin peptides that preferentially bound to the HLA-DQ trans-dimer in DQ8/DQ2 heterozygotes after deamidation, and other deamidated peptides that preferentially bound to the HLA-DQ8 cis-dimer. While healthy controls and T1D patients displayed similar reactivities, autoreactive $\mathrm{T}$ cells from most patients produced proinflammatory IFN- $\gamma$ in response to cognate antigen stimulation, in contrast to regulatory IL-10 responses in controls.

Neoepitopes generated by differences in MHC binding registers. Insulin is considered a key autoantigen in the NOD mouse model of autoimmune diabetes, as genetic manipulation to abolish response to the insulin $\mathrm{B}$ chain $\mathrm{B}: 9-23$ peptide prevents diabetes (165). Unanue and Eisenbarth/Kappler/Michels defined key molecular interactions of insulin peptides with the NOD mouse I-Ag7 MHC-II molecule, which is remarkably similar to HLA-DQ8 (166) in both sequence and binding features for insulin peptides (167). Unanue's group $(161,162,168)$ identified two registers in which peptides encompassing the insulin B:9-23 epitope bind to I-Ag7: register 1 (B:12-20) and register 2 (B:13-21). Type A CD4 ${ }^{+}$ $\mathrm{T}$ cells recognize insulin presented by APCs, and these T cells are deleted in the thymus through presentation via register 2. Type $B$ insulin-reactive $\mathrm{T}$ cells do not react with insulin protein processed by APCs but respond to soluble B chain peptide when weakly bound by $\mathrm{I}-\mathrm{Ag} 7$ in register 1 . Type $\mathrm{B} \mathrm{CD} 4^{+} \mathrm{T}$ cells are not deleted in the thymus and become activated by APCs in islets (162). Thus, a single amino acid shift of the B chain peptide bound to I-Ag7 determines whether $\mathrm{CD} 4^{+} \mathrm{T}$ cells recognize peptides generated by insulin processing and allows escape from negative selection. In essence, differences in MHC register usage determines whether a peptide is presented as a "neoepitope," as the same peptide was not presented in this register in the thymus.

Kappler's group described a register 3 in which two peptides containing the critical amino acid residues of insulin B:9-23 (B:920 and B:9-21) bind poorly to the I-Ag7 molecule $(86,169)$. According to these authors, most, if not all, NOD mouse CD $4^{+} \mathrm{T}$ cells reacting against $\mathrm{B}: 9-23$ target this peptide in the low-affinity register 3. These T cells can be divided into two types based on whether their response is improved or inhibited by glycine substitution at the B21 glutamic acid at the peptide's p8 position. Modifying the wild-type insulin $\mathrm{B}: 9-23$ peptide amino acid sequence at positions p8 and/or p9 (p8E/p9R) into p8G/p9E- and p8E/p9E-generated mimotopes that bind to $\mathrm{I}-\mathrm{Ag} 7$ in register 3 increased the binding affinity with insulin-specific TCRs and favored the activation of higher-affinity insulin-specific T cells in NOD mice (169). Register 3 presentation may not occur in the thymus, possibly explaining how insulin-specific $\mathrm{CD} 4^{+} \mathrm{T}$ cells escape negative selection. Despite unresolved differences related to registers used in these studies, these observations support the concept that differences in MHC register use are key to disease development and lead to the presentation of native antigens as neoepitopes. Similar mechanisms may be operative in patients: HLA-DQ8-restricted CD4 ${ }^{+} \mathrm{T}$ lymphocytes may target insulin peptides in a low-affinity binding register similar to the NOD register $3(170,171)$. Ultimately, differences in HLA-peptide complex interactions can impact responding $\mathrm{T}$ cell activation and phenotypes and synergize with the reduced insulin expression in the thymus that is associated with predisposing insulin gene variants. Moreover, $\mathrm{CD} 4^{+} \mathrm{T}$ cells from T1D patients display abnormal immunological synapsis associated with escape from negative selection and enhanced effector responses upon encounter with cognate antigen (172).

Neoepitopes generated by peptide fusion. Neoepitopes are also formed by fusion of peptides from two proteins, termed hybrid peptides, that are not genetically encoded and are high-affinity $\mathrm{T}$ cell targets (173). Hybrid peptides include those resulting from the fusion of proinsulin C-peptide fragments and other $\beta$ cell secretory granule proteins, such as chromogranin, IAPP, or neuropeptide $\mathrm{Y}$ (NPY). Perhaps the formation of hybrid peptides explains the essential role of insulin and chromogranin in diabetes development in NOD mice $(165,174)$. Hybrid peptides may result from proteolytic hydrolysis of peptide bonds in the presence of naturally occurring cleavage products. Insulin and other secretory proteins are packaged together in secretory granules, which may favor reversed proteolytic transpeptidation. $\mathrm{CD} 4^{+} \mathrm{T}$ cells that react against hybrid peptides were identified in NOD mice as well as islet-infiltrating cells isolated from deceased T1D patients $(173,175)$.

Neoepitopes generated by aberrant translational products. The generation of defective ribosomal products (DRiPs) from the proinsulin gene is another recently discovered mechanism leading to production of $\mathrm{T}$ cell-targeted $\beta$ cell neoepitopes. $\beta$ Cells generate DRiP neoepitopes using an alternative initiation site for translation and by translating the $3^{\prime}$ UTR (176). T cell reactivity against proinsulin DRiPs was tested in peripheral blood samples from T1D patients, and proliferative responses were observed in most. Strong T cell responses to DRiPs were detected in individuals with predisposing HLA-DQ types, such as HLA-DQ8/DQ2, who can express HLA-DQ trans-dimers (HLA-DQ8trans, DQA1 ${ }^{*} 05: 01 /$ DQB1 ${ }^{\star} 03: 02$ or HLA-DQ2trans, DQA1 $\left.{ }^{\star} 03: 01 / D Q B 1{ }^{*} 02: 01\right) . T$ cell responses to DRiPs were not observed in rare patients carrying T1D-protective HLA-DQ or insulin gene haplotypes, consistent with the concept that both genes impact thymic selection of insulin-reactive T cells.

The proinsulin UTR includes two SNPs in tight linkage disequilibrium with insulin VNTR variants associated with T1D risk and the modulation of insulin gene transcription in the thymus (91, 92). The presence of these SNPs in the UTR produces several DRiP variants. T cell responses against DRiPs containing amino acid residues encoded by predisposing or protective haplotypes were strongly correlated, suggesting that the UTR SNPs did not influence immunogenicity and may not be critical for HLA-DQ binding. Dendritic cells processed and presented proinsulin DRiPs, 
preferentially via the HLA-DQ8trans, and patient T cells exclusively responded by producing IFN- $\gamma$ and granzyme B. HLA-A2 can also present DRiPs, and T1D patients had higher frequencies of DRiP-specific CD8 ${ }^{+}$Teffs than healthy subjects. DRiP-specific $\mathrm{CD}^{+} \mathrm{T}$ cells killed HLA-A2-positive human islet cells in vitro, and pretreating the islet cells with high glucose and proinflammatory cytokines potentiated the cytotoxic action. Proinsulin DRiPs were formed under thapsigargin-induced experimental ER stress, a form of stress characterized by calcium depletion in the ER and increased cytoplasmic calcium levels, in contrast to classical ER stress caused by accumulation of misfolded proteins. Thus, in the T1D pancreas, ER stress and inflammation impair $\beta$ cell function by increasing production of autoantigens (147), and DRiPs could trigger and enhance T cell-mediated killing of $\beta$ cells (176).

\section{Ex vivo studies of T cells in T1D-relevant tissues}

Investigations of antigen-specific $\mathrm{T}$ cells from T1D-relevant tissues are rare. Earlier studies detected $\mathrm{CD} 4^{+} \mathrm{T}$ cells against insulin and/or GAD65 in the pancreatic lymph nodes (PLNs) or islets obtained from a few deceased T1D patients (57). GAD65-reactive $\mathrm{CD} 4^{+} \mathrm{T}$ cells were detected in the circulation and lymph nodes draining the transplanted pancreas in a T1D recipient who lost graft function due to recurrent autoimmunity (109), and GAD65reactive $\mathrm{CD}^{+} \mathrm{T}$ cells from pancreas transplant recipients killed cells when co-transplanted with human islets in immunodeficient mice (109). Autoimmune $\beta$ cell damage was reported in humanized mice grafted with immune cells from a T1D patient $(177,178)$. Proinsulin-specific $(61,63)$ and IGRP-reactive CD8 ${ }^{+}$T cells $(109)$ are also cytotoxic in vitro. Insulin-reactive $\mathrm{CD} 4^{+} \mathrm{T}$ cells from $\mathrm{T} 1 \mathrm{D}$ donor islets targeted a PTM epitope in the insulin A chain (60), which was presented by HLA-DR4 (DRB1 ${ }^{*} 04$ :01, but could also be presented by ${ }^{\star} 04: 04$ and $\left.{ }^{*} 04: 05\right)$. Of $53 \mathrm{CD}^{+} \mathrm{T}$ cell clones (179), 47 unique clonotypes were identified, including 8 recognizing proinsulin presented by HLA-DQ8; $26 \%$ of these clones targeted 6 distinct but overlapping epitopes in the C-peptide of proinsulin. These were presented by the HLA-DQ trans-heterodimer that forms in HLA-DQ2/-DQ8 heterozygotes using DQA1 ${ }^{*}$ 05:01 and $\mathrm{DQB1}{ }^{*} 03: 02$. More recently, collaborative efforts supported by $\mathrm{nPOD}$ have allowed expanded analyses of islet-infiltrating $\mathrm{T}$ cells from T1D organ donors. Islets were purified using standard isolation protocols and distributed to several laboratories, which isolated islet-infiltrating $\mathrm{T}$ cells and examined antigen specificities, phenotypic features, and TCR sequences.

Babon et al. (175) obtained islet-infiltrating $\mathrm{T}$ cells from 9 donors between 6 and 30 years old with 2-20 years since T1D diagnosis. Representing the largest analysis to date of islet-infiltrating $\mathrm{T}$ cells from T1D donors, the study explored the largest number of antigen specificities. More than $250 \mathrm{~T}$ cell lines or clones were derived. Lines were obtained from all T1D donors, but isletinfiltrating $\mathrm{T}$ cells were not recovered from control donors, with one exception. Thus, unlike autoreactive T cells detected in blood, lymphocytic islet infiltration is highly specific for T1D. Of 50 lines examined for autoreactivity so far, 19 reacted against a variety of known autoantigens, including PTM epitopes (180) and hybrid peptides (173). These autoreactive T cells secreted IFN- $\gamma$ and other inflammatory cytokines, consistent with an effector phenotype. This study's major finding is the broad repertoire and heterogene- ity of the $\mathrm{T}$ cell responses, which may reflect differences in HLA restriction, environmental exposures, and disease stage. However, a small fraction of islet-infiltrating $\mathrm{T}$ cell lines and clones reacted to known autoantigen epitopes. Given the broad range of disease duration, these findings match pathology studies showing that islet autoimmunity continues for years after diagnosis.

Michels at al. (181) analyzed islet-infiltrating $\mathrm{T}$ cells from nPOD donors, focusing on proinsulin-specific $\mathrm{CD} 4^{+} \mathrm{T}$ cells. The study included 3 nPOD T1D donors overlapping with those of Babon et al. (175) and nPOD donor 6323 examined by Seay et al. (182), described below. These donors were 6, 14, and 19 years old, had T1D for 2, 3, and 6 years, respectively, and displayed insulitis in the pancreatic islets. Sequencing of infiltrating T cells' TCR genes revealed diverse repertoires, but certain TCRs were repeatedly detected, suggesting some level of clonal expansion. Many of these TCR sequences were found in multiple islets. TCRs expressed by islet-infiltrating $\mathrm{T}$ cells reacted against the insulin B:9-23 epitope and were restricted by HLA-DQ8. Reactivity to a 19-35 epitope of C-peptide reported in the islets of a previously discussed T1D donor (179) was reproduced. However, the majority of the TCRs examined did not respond to proinsulin/insulin epitopes, consistent with the broad reactivity reported by Babon et al. (175).

Seay et al. (182) studied pancreas, PLN, spleen, irrelevant lymph nodes, and peripheral blood from 18 nPOD donors diagnosed with T1D 4-32 years prior to their death at ages 11-44 years. The researchers conducted high-throughput immunosequencing of the TCR $\beta$-chain (TRB) to investigate TCR repertoire diversity; TCR sharing among blood and various tissues in T cell subsets (CD4 ${ }^{+}$conventional T [Tconv] cells; $\mathrm{CD}^{+}{ }^{+}$Tregs; $\mathrm{CD} 8^{+} \mathrm{T}$ cells); TCR clonal expansion in selected compartments; and whether any T1Dassociated TCRs were public, or shared, among patients. TRB sharing across compartments and TCR diversity were similar in patients and controls, revealing limited evidence for receptor biases. Moreover, there was low CD3 $\beta$ sharing across tissues, and shared sequences were not known to target T1D autoantigens. In both groups, there was minimal TCR overlap between PLN Tregs and Tconv cells, which may not support T-lineage instability and plasticity contributing to T1D through the interconversion of Tregs to Tconv effector cells. However, those TCRs matching sequences with previously reported autoreactive $\mathrm{T}$ cells were highly enriched in the T1D donors. These included autoreactive $\mathrm{T}$ cells directed against epitopes of proinsulin C-peptide 19-35 previously identified in the islets of a T1D donor (179) and several GAD65-reactive clones reported in blood of prediabetic individuals and patients (183). These proinsulin and GAD65 TCR sequences were found in the PLN of some T1D donors. CD4 ${ }^{+} \mathrm{T}$ cells targeting the GAD65 555567 epitope were described in peripheral blood of patients $(68,184)$.

Seay et al. (182) described a TCR sequence matching a previously reported GAD65 clone (GAD4.13) that represented approximately $25 \%$ of the TCR sequences found in the PLN of a T1D donor. In this donor, the CDR3 $\beta$ sequence was the most abundant in PLN Treg and $\mathrm{CD}^{+} \mathrm{T}$ cell subsets, providing initial evidence of strong clonal dominance. The GAD4.13 CDR3 $\beta$ sequence was detected in several tissue compartments in about $40 \%$ of T1D donors and in islet-infiltrating T cells in nPOD donor 6323. Approximately $14 \%$ of 399 CD3 $\beta$ sequences identified in this donor's isletinfiltrating $\mathrm{CD}^{+} \mathrm{T}$ cells were also in the PLN, and most of these 
shared sequences were detected in blood, yet there was minimal overlap between the islet and PLN compartment and no overlap with circulating $\mathrm{CD} 4^{+}$Tconv cells. Together with the data of Michels et al. on the same donor (181), these findings support the existence of public TCRs shared among patients. Additional evidence for public TCRs derives from the observation that TCR sequences of GAD65 autoreactive $\mathrm{CD} 4^{+} \mathrm{T}$ cells from a patient with T1D recurrence in the transplanted pancreas (109) overlapped with sequences from a large number of the nPOD T1D donors studied by Seay et al. (182).

\section{Closing remarks}

Autoreactive $\mathrm{T}$ cells targeting a broad repertoire of antigens and epitopes are considered the main mediators of $\beta$ cell death in T1D. Given the diversity of islet autoimmune responses and patient heterogeneity, it is challenging to discern whether any responses are more pathogenic than others. Growing evidence supports the targeting of "neoepitopes" that result from post-translational modification of native antigens, fusion of peptides derived from different proteins, alternative splicing, and defective ribosomal intermediate products. T cells reacting with neoepitopes may have higher affinity and stronger pathogenic potential if central tolerance mechanisms do not apply to these epitopes, which may not be expressed by tolerogenic thymic medullary epithelial cells or tolerogenic stromal cells and APCs in peripheral lymphoid tissues (185-187). Many neoepitopes may only be expressed in the target organ; in particular, neoepitopes involving insulin may be limited to $\beta$ cells, and stress and inflammation may influence their expression. The role of neoepitopes is a critical research area where we may learn more about impaired tolerance mechanisms and whether responses to neoepitopes are primary autoimmune responses and major disease drivers. If future studies can identify key disease driver epitopes, there would be major implications for disease prediction, prevention, and therapy, especially for antigen-specific therapies.

It is currently unknown if a proportion of autoreactive $\mathrm{T}$ cells can react with viral epitopes, whether or not they crossreact with islet antigens. Given the extensive literature associating T1D with enterovirus infection of the islets (30), the association of insulitis with hyperexpression of HLA-I molecules, and the predominance of $\mathrm{CD}^{+} \mathrm{T}$ cells in islet infiltrates, it is reasonable to hypothesize that a significant proportion of isletinfiltrating $\mathrm{CD}^{+} \mathrm{T}$ cells may react against viral epitopes (Figures 2 and 3). If so, $\mathrm{CD}^{+} \mathrm{T}$ cells against viruses may contribute to T1D pathogenesis by eliminating infected $\beta$ cells presenting viral epitopes in the context of HLA-I hyperexpression. New investigations should attempt to identify $\mathrm{CD} 8^{+} \mathrm{T}$ cells against T1Dassociated viruses, especially for epitopes that are good binders for T1D-predisposing HLA molecules; determination of crossreactivity with autoantigens should be also explored. Moreover, antiviral responses may be depressed in T1D patients, at least temporarily. For example, impaired responses were linked to subsequent development of insulin autoimmunity in early life (127). Perhaps responses to viral antigens that cross-react with islet autoantigens are more susceptible to regulation: weaker antiviral responses may favor the persistence of viral infections. Addressing these major unanswered questions could impact our understanding of the potential role of viruses and overall disease pathogenesis, and design of future therapies.
The ability to detect autoreactive T cells in the circulation has improved dramatically, but their common presence in healthy subjects requires assessing autoreactive $\mathrm{T}$ cell phenotypes and functions to aid in interpretation of positive results. Recent studies of T1D and prediabetic organ donors have examined pathology and autoreactive $\mathrm{T}$ cells in the pancreas, focusing on isletinfiltrating $\mathrm{T}$ cells and those in lymphoid tissues. These studies provide insight into the $\mathrm{T}$ cells associated with insulitis and allow comparisons with peripheral blood readouts. TCR analysis in blood, pancreas, and lymphoid tissues may help firmly establish whether detection of certain autoreactive $\mathrm{T}$ cells with particular phenotypes can be a biomarker of ongoing insulitis. Initial evidence for limited TCR sharing among patients could represent key responses and perhaps therapeutic targets. Further studies investigating TCR sharing between antigen-specific Tconv cells and Tregs reacting to the same epitope with identical HLA restriction could help define to what degree Tregs compete with Tconv cells for binding to a shared cognate epitope. If TCR sharing is low, opportunities may also open for selective therapeutic targeting of Teffs or Tregs. For example, there may not be natural Tregs specific for neoepitopes.

Ongoing pathology studies of pancreata obtained near T1D onset or afterward are revealing that only a proportion of islets are affected at any given time. It remains unclear when $\mathrm{T}$ cells begin infiltrating the islets relative to the initiation of autoimmunity as marked by autoantibody conversion. There is interest in defining which classes of autoimmune responses are detected first, under the hypothesis that initial responses are triggers and possibly major disease drivers. Perhaps responses to neoepitopes represent the earliest and most pathogenic responses, with responses to native epitopes playing a secondary role. An alternative hypothesis is that more benign, initial responses are directed toward native antigens, are fairly regulated, and produce modest inflammation and little damage to $\beta$ cells; however, persisting and increasing islet inflammation, $\beta$ cell stress, and perhaps viral infections could lead to the generation of neoepitopes and trigger more aggressive autoimmunity. Generation of novel reagents that track autoantibody and $\mathrm{T}$ cell responses against neoepitopes will enable interrogation of archived blood samples from at-risk relatives in natural history studies, some of which begin at birth. Studies of clinical cohorts and expanded numbers of organ donors will be critical to addressing outstanding questions about autoreactive T cells in T1D.

\section{Acknowledgments}

Studies by the author related to this topic were supported by grants from the NIH (R01 DK070011), the JDRF (research grants 25-2013268, 17-2011-594, 17-2012-3), the Leona M. and Harry B. Helmsley Charitable Trust (George Eisenbarth nPOD Award for Team Science, 2015PG-T1D052), and the Diabetes Research Institute Foundation, Hollywood, Florida.

Address correspondence to: Alberto Pugliese, Diabetes Research Institute, University of Miami Miller School of Medicine, $1450 \mathrm{NW}$ 10th Avenue, Miami, Florida 33136, USA. Phone: 305.243.5348; Email: apuglies@med.miami.edu. 
1. Atkinson MA, Eisenbarth GS, Michels AW. Type 1 diabetes. Lancet. 2014;383(9911):69-82.

2. Ziegler AG, et al. Seroconversion to multiple islet autoantibodies and risk of progression to diabetes in children. JAMA. 2013;309(23):2473-2479.

3. Noble JA, et al. HLA class I and genetic susceptibility to type 1 diabetes: results from the Type 1 Diabetes Genetics Consortium. Diabetes. 2010;59(11):2972-2979.

4. Erlich H, et al. HLA DR-DQ haplotypes and genotypes and type 1 diabetes risk: analysis of the type 1 diabetes genetics consortium families. Diabetes. 2008;57(4):1084-1092.

5. van Lummel M, et al. Type 1 diabetes-associated HLA-DQ8 transdimer accommodates a unique peptide repertoire. J Biol Chem. 2012;287(12):9514-9524.

6. Nejentsev S, et al. Localization of type 1 diabetes susceptibility to the MHC class I genes HLA-B and HLA-A. Nature. 2007;450(7171):887-892.

7. Roep BO, Peakman M. Antigen targets of type 1 diabetes autoimmunity. Cold Spring Harb Perspect Med.2012;2(4):a007781.

8. Velthuis JH, et al. Simultaneous detection of circulating autoreactive CD8+ T-cells specific for different islet cell-associated epitopes using combinatorial MHC multimers. Diabetes. 2010;59(7):1721-1730.

9. Unger WW, et al. Discovery of low-affinity preproinsulin epitopes and detection of autoreactive CD8 T-cells using combinatorial MHC multimers. J Autoimmun. 2011;37(3):151-159.

10. Uchtenhagen $\mathrm{H}$, et al. Efficient ex vivo analysis of CD4+ T-cell responses using combinatorial HLA class II tetramer staining. Nat Commun. 2016;7:12614.

11. Rowe PA, Campbell-Thompson ML, Schatz DA, Atkinson MA. The pancreas in human type 1 diabetes. Semin Immunopathol. 2011;33(1):29-43.

12. Foulis AK, Liddle CN, Farquharson MA, Richmond JA, Weir RS. The histopathology of the pancreas in type 1 (insulin-dependent) diabetes mellitus: a 25-year review of deaths in patients under 20 years of age in the United Kingdom. Diabetologia. 1986;29(5):267-274.

13. Imagawa A, et al. Pancreatic biopsy as a procedure for detecting in situ autoimmune phenomena in type 1 diabetes: close correlation between serological markers and histological evidence of cellular autoimmunity. Diabetes. 2001;50(6):1269-1273.

14. Krogvold L, et al. Pancreatic biopsy by minimal tail resection in live adult patients at the onset of type 1 diabetes: experiences from the DiViD study. Diabetologia. 2014;57(4):841-843.

15. Pugliese A, et al. The Juvenile Diabetes Research Foundation Network for Pancreatic Organ Donors with Diabetes (nPOD) Program: goals, operational model and emerging findings. Pediatr Diabetes. 2014;15(1):1-9.

16. Campbell-Thompson M, et al. Insulitis and $\beta$-cell mass in the natural history of type 1 diabetes. Diabetes. 2016;65(3):719-731.

17. In't Veld P. Insulitis in human type 1 diabetes: the quest for an elusive lesion. Islets. 2011;3(4):131-138.

18. Campbell-Thompson ML, et al. The diagnosis of insulitis in human type 1 diabetes. Diabetologia. 2013;56(11):2541-2543.
19. Pugliese A. Insulitis in the pathogenesis of type 1 diabetes. Pediatr Diabetes. 2016;17 Suppl 22:31-36.

20. Reddy S, et al. Analysis of peri-islet CD45-positive leucocytic infiltrates in long-standing type 1 diabetic patients. Diabetologia. 2015;58(5):1024-1035.

21. Krogvold L, et al. Insulitis and characterisation of infiltrating $\mathrm{T}$ cells in surgical pancreatic tail resections from patients at onset of type 1 diabetes. Diabetologia. 2016;59(3):492-501.

22. Eisenbarth GS. Banting Lecture 2009: an unfinished journey: molecular pathogenesis to prevention of type 1A diabetes. Diabetes. 2010;59(4):759-774.

23. Coppieters KT, et al. Demonstration of isletautoreactive CD8 T cells in insulitic lesions from recent onset and long-term type 1 diabetes patients. J Exp Med. 2012;209(1):51-60.

24. Keenan HA, et al. Residual insulin production and pancreatic $\beta$-cell turnover after 50 years of diabetes: Joslin Medalist Study. Diabetes. 2010;59(11):2846-2853.

25. Foulis AK, Farquharson MA, Hardman R. Aberrant expression of class II major histocompatibility complex molecules by B cells and hyperexpression of class I major histocompatibility complex molecules by insulin containing islets in type 1 (insulin-dependent) diabetes mellitus. Diabetologia. 1987;30(5):333-343.

26. Richardson SJ, et al. Islet cell hyperexpression of HLA class I antigens: a defining feature in type 1 diabetes. Diabetologia. 2016;59(11):2448-2458.

27. Bottazzo GF, Dean BM, McNally JM, MacKay EH, Swift PG, Gamble DR. In situ characterization of autoimmune phenomena and expression of HLA molecules in the pancreas in diabetic insulitis. N Engl JMed. 1985;313(6):353-360.

28. Lernmark A, et al. Heterogeneity of islet pathology in two infants with recent onset diabetes mellitus. Virchows Arch. 1995;425(6):631-640.

29. Krogvold L, et al. Detection of a low-grade enteroviral infection in the islets of Langerhans of living patients newly diagnosed with type 1 diabetes. Diabetes. 2015;64(5):1682-1687.

30. Hyöty H. Viruses in type 1 diabetes. Pediatr Diabetes. 2016;17 Suppl 22:56-64.

31. Pujol-Borrell R, et al. HLA class II induction in human islet cells by interferon-gamma plus tumour necrosis factor or lymphotoxin. Nature. 1987;326(6110):304-306.

32. Campbell IL, Oxbrow L, West J, Harrison LC. Regulation of MHC protein expression in pancreatic beta-cells by interferon-gamma and tumor necrosis factor-alpha. Mol Endocrinol. 1988;2(2):101-107.

33. Lo D, et al. Diabetes and tolerance in transgenic mice expressing class II MHC molecules in pancreatic beta cells. Cell. 1988;53(1):159-168.

34. Böhme J, et al. Transgenic mice with I-A on islet cells are normoglycemic but immunologically intolerant. Science. 1989;244(4909):1179-1183.

35. Sarvetnick N, Liggitt D, Pitts SL, Hansen SE, Stewart TA. Insulin-dependent diabetes mellitus induced in transgenic mice by ectopic expression of class II MHC and interferon-gamma. Cell. 1988;52(5):773-782.

36. Bottazzo GF. Lawrence lecture. Death of a beta cell: homicide or suicide? Diabet Med. 1986;3(2):119-130.
37. Gianani R, et al. Initial results of screening of nondiabetic organ donors for expression of islet autoantibodies. JClin Endocrinol Metab. 2006;91(5):1855-1861.

38. Tauriainen S, Salmela K, Rantala I, Knip M, Hyöty H. Collecting high-quality pancreatic tissue for experimental study from organ donors with signs of $\beta$-cell autoimmunity. Diabetes Metab Res Rev. 2010;26(7):585-592.

39. Wasserfall C, et al. Validation of a rapid type 1 diabetes autoantibody screening assay for community-based screening of organ donors to identify subjects at increased risk for the disease. Clin Exp Immunol. 2016;185(1):33-41.

40. Burke GW, Posgai AL, Wasserfall CH, Atkinson MA, Pugliese A. Raising awareness: the need to promote allocation of pancreata from rare nondiabetic donors with pancreatic islet autoimmunity to type 1 diabetes research. Am J Transplant. 2017;17(1):306-307.

41. In't Veld P, et al. Screening for insulitis in adult autoantibody-positive organ donors. Diabetes. 2007;56(9):2400-2404.

42. Wiberg A, et al. Characterization of human organ donors testing positive for type 1 diabetesassociated autoantibodies. Clin Exp Immunol. 2015;182(3):278-288.

43. Oikarinen $\mathrm{M}$, et al. Analysis of pancreas tissue in a child positive for islet cell antibodies. Diabetologia. 2008;51(10):1796-1802.

44. Rodriguez-Calvo $\mathrm{T}$, et al. Increase in pancreatic proinsulin and preservation of $\beta$-cell mass in autoantibody-positive donors prior to type 1 diabetes onset. Diabetes. 2017;66(5):1334-1345.

45. Diedisheim M, Mallone R, Boitard C, Larger E. $\beta$-cell mass in nondiabetic autoantibody-positive subjects: an analysis based on the Network for Pancreatic Organ Donors Database. JClin Endocrinol Metab. 2016;101(4):1390-1397.

46. Sosenko JM, et al. Acceleration of the loss of the first-phase insulin response during the progression to type 1 diabetes in diabetes prevention trial-type 1 participants. Diabetes. 2013;62(12):4179-4183.

47. Sims EK, et al. Elevations in the fasting serum proinsulin-to-c-peptide ratio precede the onset of type 1 diabetes. Diabetes Care. 2016;39(9):1519-1526.

48. Ferrannini E, Mari A, Nofrate V, Sosenko JM, Skyler JS, DPT-1 Study Group. Progression to diabetes in relatives of type 1 diabetic patients: mechanisms and mode of onset. Diabetes. 2010;59(3):679-685.

49. Herold KC, et al. $\beta$ cell death and dysfunction during type 1 diabetes development in at-risk individuals. J Clin Invest. 2015;125(3):1163-1173.

50. Keller RJ. Cellular immunity to human insulin in individuals at high risk for the development of type I diabetes mellitus. J Autoimmun. 1990;3(3):321-327.

51. Rudy G, et al. Similar peptides from two beta cell autoantigens, proinsulin and glutamic acid decarboxylase, stimulate $\mathrm{T}$ cells of individuals at risk for insulin-dependent diabetes. Mol Med. 1995;1(6):625-633.

52. Alleva DG, et al. A disease-associated cellular immune response in type 1 diabetics to an immunodominant epitope of insulin. JClin Invest. 2001;107(2):173-180. 
53. Durinovic-Belló I, Boehm BO, Ziegler AG. Predominantly recognized proinsulin $\mathrm{T}$ helper cell epitopes in individuals with and without islet cell autoimmunity. J Autoimmun. 2002;18(1):55-66.

54. Narendran P, Williams AJ, Elsegood K, Leech NJ, Dayan CM. Humoral and cellular immune responses to proinsulin in adults with newly diagnosed type 1 diabetes. Diabetes Metab Res Rev. 2003;19(1):52-59.

55. Astill TP, Ellis RJ, Arif S, Tree TI, Peakman M. Promiscuous binding of proinsulin peptides to type 1 diabetes-permissive and -protective HLA class II molecules. Diabetologia. 2003;46(4):496-503.

56. Ott PA, et al. T cells recognize multiple GAD65 and proinsulin epitopes in human type 1 diabetes, suggesting determinant spreading. J Clin Immunol. 2004;24(4):327-339.

57. Kent SC, et al. Expanded T cells from pancreatic lymph nodes of type 1 diabetic subjects recognize an insulin epitope. Nature. 2005;435(7039):224-228.

58. Toma A, et al. Recognition of a subregion of human proinsulin by class I-restricted $\mathrm{T}$ cells in type 1 diabetic patients. Proc Natl Acad Sci U S A. 2005;102(30):10581-10586.

59. Hassainya $Y$, et al. Identification of naturally processed HLA-A2-restricted proinsulin epitopes by reverse immunology. Diabetes. 2005;54(7):2053-2059.

60. Mannering SI, et al. The insulin A-chain epitope recognized by human $\mathrm{T}$ cells is posttranslationally modified. JExp Med. 2005;202(9):1191-1197.

61. Skowera A, et al. CTLs are targeted to kill beta cells in patients with type 1 diabetes through recognition of a glucose-regulated preproinsulin epitope. J Clin Invest. 2008;118(10):3390-3402.

62. Abreu JR, et al. CD8 T cell autoreactivity to preproinsulin epitopes with very low human leucocyte antigen class I binding affinity. Clin Exp Immunol. 2012;170(1):57-65.

63. Kronenberg D, et al. Circulating preproinsulin signal peptide-specific CD8 T cells restricted by the susceptibility molecule HLA-A24 are expanded at onset of type 1 diabetes and kill $\beta$-cells. Diabetes. 2012;61(7):1752-1759.

64. Atkinson MA, et al. Response of peripheral-blood mononuclear cells to glutamate decarboxylase in insulin-dependent diabetes. Lancet. 1992;339(8791):458-459.

65. Panina-Bordignon P, et al. Cytotoxic T cells specific for glutamic acid decarboxylase in autoimmune diabetes. JExp Med. 1995;181(5):1923-1927.

66. Durinovic-Bellò I, Hummel M, Ziegler AG. Cellular immune response to diverse islet cell antigens in IDDM. Diabetes. 1996;45(6):795-800.

67. Harfouch-Hammoud E, et al. Identification of peptides from autoantigens GAD65 and IA-2 that bind to HLA class II molecules predisposing to or protecting from type 1 diabetes. Diabetes. 1999;48(10):1937-1947.

68. Reijonen H, et al. Detection of GAD65-specific T-cells by major histocompatibility complex class II tetramers in type 1 diabetic patients and at-risk subjects. Diabetes. 2002;51(5):1375-1382.

69. Viglietta V, Kent SC, Orban T, Hafler DA. GAD65-reactive $T$ cells are activated in patients with autoimmune type 1 a diabetes. J Clin Invest.
2002;109(7):895-903.

70. Reijonen H, et al. GAD65-specific CD4+ T-cells with high antigen avidity are prevalent in peripheral blood of patients with type 1 diabetes. Diabe tes. 2004;53(8):1987-1994.

71. Mallone R, et al. Differential recognition and activation thresholds in human autoreactive GADspecific T-cells. Diabetes. 2004;53(4):971-977.

72. Chow IT, et al. Assessment of CD4+ T cell responses to glutamic acid decarboxylase 65 using DQ8 tetramers reveals a pathogenic role of GAD65 121-140 and GAD65 250-266 in T1D development. PLoS One. 2014;9(11):e112882.

73. Honeyman MC, Stone NL, Harrison LC. T-cell epitopes in type 1 diabetes autoantigen tyrosine phosphatase IA-2: potential for mimicry with rotavirus and other environmental agents. $\mathrm{Mol}$ Med.1998;4(4):231-239.

74. Peakman M, et al. Naturally processed and presented epitopes of the islet cell autoantigen IA-2 eluted from HLA-DR4. J Clin Invest. 1999;104(10):1449-1457.

75. Hawkes CJ, et al. T-cell lines reactive to an immunodominant epitope of the tyrosine phosphatase-like autoantigen IA-2 in type 1 diabetes. Diabetes. 2000;49(3):356-366.

76. Lieberman SM, et al. Identification of the beta cell antigen targeted by a prevalent population of pathogenic CD8+ T cells in autoimmune diabetes. Proc Natl Acad Sci U S A. 2003;100(14):8384-8388.

77. Mukherjee R, Wagar D, Stephens TA, Lee-Chan $\mathrm{E}$, Singh B. Identification of CD4+ T cell-specific epitopes of islet-specific glucose-6-phosphatase catalytic subunit-related protein: a novel beta cell autoantigen in type 1 diabetes. J Immunol. 2005;174(9):5306-5315.

78. Ouyang Q, et al. Recognition of HLA class I-restricted beta-cell epitopes in type 1 diabetes. Diabetes. 2006;55(11):3068-3074.

79. Standifer NE, et al. Identification of novel HLA-A ${ }^{*}$ 0201-restricted epitopes in recent-onset type 1 diabetic subjects and antibody-positive relatives. Diabetes. 2006;55(11):3061-3067.

80. Yang J, et al. Islet-specific glucose-6-phosphatase catalytic subunit-related protein-reactive CD4+ T cells in human subjects. J Immunol. 2006;176(5):2781-2789.

81. Wenzlau JM, et al. The cation efflux transporter ZnT8 (Slc30A8) is a major autoantigen in human type 1 diabetes. Proc Natl Acad Sci U S A. 2007;104(43):17040-17045.

82. Énée É, et al. ZnT8 is a major CD8+ T cellrecognized autoantigen in pediatric type 1 diabetes. Diabetes. 2012;61(7):1779-1784.

83. Scotto M, et al. Zinc transporter (ZnT)8(186-194) is an immunodominant CD8 + $\mathrm{T}$ cell epitope in HLA-A2+ type 1 diabetic patients. Diabetologia 2012;55(7):2026-2031.

84. Li S, et al. Identification of novel HLA-A 0201-restricted cytotoxic T lymphocyte epitopes from Zinc Transporter 8. Vaccine. 2013;31(12):1610-1615.

85. Chujo D, Foucat E, Nguyen TS, Chaussabel D, Banchereau J, Ueno H. ZnT8-Specific CD4+ T cells display distinct cytokine expression profiles between type 1 diabetes patients and healthy adults. PLoS One. 2013;8(2):e55595.
86. Stadinski BD, et al. Chromogranin A is an autoantigen in type 1 diabetes. Nat Immunol. 2010;11(3):225-231.

87. Gottlieb PA, et al. Chromogranin A is a T cell antigen in human type 1 diabetes. J Autoimmun. 2014;50:38-41

88. Takeyama $\mathrm{N}$, et al. Localization of insulinoma associated protein 2, IA-2 in mouse neuroendocrine tissues using two novel monoclonal antibodies. Life Sci. 2009;84(19-20):678-687.

89. Mally MI, Cirulli V, Otonkoski T, Soto G, Hayek A. Ontogeny and tissue distribution of human GAD expression. Diabetes. 1996;45(4):496-501.

90. Kyewski B, Klein L. A central role for central tolerance. Annu Rev Immunol. 2006;24:571-606.

91. Pugliese A, et al. The insulin gene is transcribed in the human thymus and transcription levels correlated with allelic variation at the INS VNTRIDDM2 susceptibility locus for type 1 diabetes. Nat Genet. 1997;15(3):293-297.

92. Vafiadis P, et al. Insulin expression in human thymus is modulated by INS VNTR alleles at the IDDM2 locus. Nat Genet. 1997;15(3):289-292.

93. Vafiadis P, et al. Class III alleles of the variable number of tandem repeat insulin polymorphism associated with silencing of thymic insulin predispose to type 1 diabetes. JClin Endocrinol Metab. 2001;86(8):3705-3710.

94. Chentoufi AA, Polychronakos C. Insulin expression levels in the thymus modulate insulinspecific autoreactive T-cell tolerance: the mechanism by which the IDDM2 locus may predispose to diabetes. Diabetes. 2002;51(5):1383-1390.

95. Thébault-Baumont K, et al. Acceleration of type 1 diabetes mellitus in proinsulin 2-deficient NOD mice. J Clin Invest. 2003;111(6):851-857.

96. Moriyama $\mathrm{H}$, et al. Evidence for a primary islet autoantigen (preproinsulin 1) for insulitis and diabetes in the nonobese diabetic mouse. Proc Natl Acad Sci U S A. 2003;100(18):10376-10381.

97. Fan Y, Rudert WA, Grupillo M, He J, Sisino G, Trucco M. Thymus-specific deletion of insulin induces autoimmune diabetes. EMBO J. 2009;28(18):2812-2824.

98. Jarchum I, DiLorenzo TP. Ins2 deficiency augments spontaneous HLA-A ${ }^{*}$ 0201-restricted $\mathrm{T}$ cell responses to insulin. J Immunol. 2010;184(2):658-665.

99. Durinovic-Belló I, et al. Class III alleles at the insulin VNTR polymorphism are associated with regulatory T-cell responses to proinsulin epitopes in HLA-DR4, DQ8 individuals. Diabetes. 2005;54 Suppl 2:S18-S24.

100.Durinovic-Belló I, Wu RP, Gersuk VH, Sanda S, Shilling HG, Nepom GT. Insulin gene VNTR genotype associates with frequency and phenotype of the autoimmune response to proinsulin. Genes Immun. 2010;11(2):188-193.

101. Bulek AM, et al. Structural basis for the killing of human beta cells by CD8(+) T cells in type 1 diabetes. Nat Immunol. 2012;13(3):283-289.

102. Mannering SI, Morris JS, Stone NL, Jensen KP, VAN Endert PM, Harrison LC. CD4+ T cell proliferation in response to GAD and proinsulin in healthy, pre-diabetic, and diabetic donors. Ann N Y Acad Sci. 2004;1037:16-21.

103. Monti P, Heninger AK, Bonifacio E. Differentiation, expansion, and homeostasis of autoreactive 
T cells in type 1 diabetes mellitus. Curr Diab Rep. 2009;9(2):113-118.

104. Oling V, Reijonen H, Simell O, Knip M, Ilonen J. Autoantigen-specific memory CD4+ T cells are prevalent early in progression to Type 1 diabetes. Cell Immunol. 2012;273(2):133-139.

105. Rigby MR, et al. Targeting of memory $T$ cells with alefacept in new-onset type 1 diabetes (T1DAL study): 12 month results of a randomised, doubleblind, placebo-controlled phase 2 trial. Lancet Diabetes Endocrinol. 2013;1(4):284-294.

106. Rigby MR, et al. Alefacept provides sustained clinical and immunological effects in newonset type 1 diabetes patients. JClin Invest. 2015;125(8):3285-3296

107. Velthuis JH, et al. Accumulation of autoreactive effector $\mathrm{T}$ cells and allo-specific regulatory $\mathrm{T}$ cells in the pancreas allograft of a type 1 diabetic recipient. Diabetologia. 2009;52(3):494-503.

108. Hilbrands R, et al. Differences in baseline lymphocyte counts and autoreactivity are associated with differences in outcome of islet cell transplantation in type 1 diabetic patients. Diabetes. 2009;58(10):2267-2276.

109. Vendrame F, et al. Recurrence of type 1 diabetes after simultaneous pancreas-kidney transplantation, despite immunosuppression, is associated with autoantibodies and pathogenic autoreactive CD4 T-cells. Diabetes. 2010;59(4):947-957.

110. Arif S, et al. Autoreactive T cell responses show proinflammatory polarization in diabetes but a regulatory phenotype in health. J Clin Invest. 2004;113(3):451-463.

111. van Lummel M, et al. Posttranslational modification of HLA-DQ binding islet autoantigens in type 1 diabetes. Diabetes. 2014;63(1):237-247.

112. Buckner JH. Mechanisms of impaired regulation by CD4(+)CD25(+)FOXP3(+) regulatory T cells in human autoimmune diseases. Nat Rev Immunol. 2010;10(12):849-859.

113. Ferraro A, et al. Expansion of Th17 cells and functional defects in $\mathrm{T}$ regulatory cells are key features of the pancreatic lymph nodes in patients with type 1 diabetes. Diabetes. 2011;60(11):2903-2913.

114. Schneider A, Rieck M, Sanda S, Pihoker C, Greenbaum C, Buckner JH. The effector T cells of diabetic subjects are resistant to regulation via CD4+ FOXP3+ regulatory T cells. JImmunol. 2008;181(10):7350-7355.

115. Pociot F, et al. Genetics of type 1 diabetes: what's next? Diabetes. 2010;59(7):1561-1571.

116. Malek TR, Castro I. Interleukin-2 receptor signaling: at the interface between tolerance and immunity. Immunity. 2010;33(2):153-165.

117. Garg G, et al. Type 1 diabetes-associated IL2RA variation lowers IL-2 signaling and contributes to diminished CD4+CD25+ regulatory T cell function. J Immunol. 2012;188(9):4644-4653.

118. Gallagher GR, et al. Viral infection of engrafted human islets leads to diabetes. Diabetes. 2015;64(4):1358-1369.

119. Kim KW, et al. Coxsackievirus B5 infection induces dysregulation of microRNAs predicted to target known type 1 diabetes risk genes in human pancreatic islets. Diabetes. 2016;65(4):996-1003.

120. Grieco FA, et al. MicroRNAs miR-23a-3p, miR23b-3p, and miR-149-5p regulate the expression of proapoptotic $\mathrm{BH} 3$-only proteins DP5 and
PUMA in human pancreatic $\beta$-cells. Diabetes. 2017;66(1):100-112.

121. Ferreira RC, et al. A type I interferon transcriptional signature precedes autoimmunity in children genetically at risk for type 1 diabetes. Diabetes. 2014;63(7):2538-2550.

122. Marroqui L, et al. Interferon- $\alpha$ mediates human beta cell HLA class I overexpression, endoplasmic reticulum stress and apoptosis, three hallmarks of early human type 1 diabetes. Diabetologia. 2017;60(4):656-667.

123. Op de Beeck A, Eizirik DL. Viral infections in type 1 diabetes mellitus - why the $\beta$ cells? Nat Rev Endocrinol. 2016;12(5):263-273.

124.Pane JA, Coulson BS. Lessons from the mouse: potential contribution of bystander lymphocyte activation by viruses to human type 1 diabetes. Diabetologia. 2015;58(6):1149-1159.

125. Coppieters KT, Wiberg A, von Herrath MG. Viral infections and molecular mimicry in type 1 diabetes. APMIS. 2012;120(12):941-949.

126.Afonso G, Mallone R. Infectious triggers in type 1 diabetes: is there a case for epitope mimicry? Diabetes Obes Metab. 2013;15 Suppl 3:82-88.

127. Ashton MP, et al. Incomplete immune response to coxsackie $B$ viruses associates with early autoimmunity against insulin. Sci Rep. 2016;6:32899.

128. Hou J, Said C, Franchi D, Dockstader P, Chatterjee NK. Antibodies to glutamic acid decarboxylase and $\mathrm{P} 2-\mathrm{C}$ peptides in sera from coxsackie virus B4-infected mice and IDDM patients. Diabetes. 1994;43(10):1260-1266.

129. Lönnrot M, et al. Antibody cross-reactivity induced by the homologous regions in glutamic acid decarboxylase (GAD65) and 2C protein of coxsackievirus B4. Childhood Diabetes in Finland Study Group. Clin Exp Immunol. 1996;104(3):398-405.

130. Tong JC, Myers MA, Mackay IR, Zimmet PZ, Rowley MJ. The PEVKEK region of the pyridoxal phosphate binding domain of GAD65 expresses a dominant $B$ cell epitope for type 1 diabetes sera. Ann N Y Acad Sci. 2002;958:182-189.

131. Härkönen T, Lankinen H, Davydova B, Hovi T, Roivainen M. Enterovirus infection can induce immune responses that cross-react with beta-cell autoantigen tyrosine phosphatase IA-2/IAR. JMed Virol. 2002;66(3):340-350.

132. Härkönen T, Paananen A, Lankinen H, Hovi T, Vaarala O, Roivainen M. Enterovirus infection may induce humoral immune response reacting with islet cell autoantigens in humans. JMed Virol. 2003;69(3):426-440.

133. Bason C, et al. In type 1 diabetes a subset of anti-coxsackievirus B4 antibodies recognize autoantigens and induce apoptosis of pancreatic beta cells. PLoS One. 2013;8(2):e57729.

134. Honeyman MC, et al. Association between rotavirus infection and pancreatic islet autoimmunity in children at risk of developing type 1 diabetes. Diabetes. 2000;49(8):1319-1324.

135. Atkinson MA, Bowman MA, Campbell L, Darrow BL, Kaufman DL, Maclaren NK. Cellular immunity to a determinant common to glutamate decarboxylase and coxsackie virus in insulin-dependent diabetes. JClin Invest. 1994;94(5):2125-2129.

136. Vreugdenhil GR, Geluk A, Ottenhoff TH, Melchers WJ, Roep BO, Galama JM. Molecular mimicry in diabetes mellitus: the homologous domain in coxsackie $\mathrm{B}$ virus protein $2 \mathrm{C}$ and islet autoantigen GAD65 is highly conserved in the coxsackie B-like enteroviruses and binds to the diabetes associated HLA-DR3 molecule. Diabetologia. 1998;41(1):40-46.

137. Ou D, Jonsen LA, Metzger DL, Tingle AJ. CD4+ and CD8+ T-cell clones from congenital rubella syndrome patients with IDDM recognize overlapping GAD65 protein epitopes. Implications for HLA class I and II allelic linkage to disease susceptibility. Hum Immunol. 1999;60(8):652-664.

138. Ou D, Mitchell LA, Metzger DL, Gillam S, Tingle AJ. Cross-reactive rubella virus and glutamic acid decarboxylase (65 and 67) protein determinants recognised by $T$ cells of patients with type I diabetes mellitus. Diabetologia. 2000;43(6):750-762.

139. Varela-Calvino R, Sgarbi G, Arif S, Peakman M. $\mathrm{T}$-cell reactivity to the $\mathrm{P} 2 \mathrm{C}$ nonstructural protein of a diabetogenic strain of coxsackievirus B4. Virology. 2000;274(1):56-64.

140. Hiemstra HS, et al. Cytomegalovirus in autoimmunity: $T$ cell crossreactivity to viral antigen and autoantigen glutamic acid decarboxylase. Proc Natl Acad Sci U S A. 2001;98(7):3988-3991.

141. Roep BO, et al. Molecular mimicry in type 1 diabetes: immune cross-reactivity between islet autoantigen and human cytomegalovirus but not Coxsackie virus. Ann N Y Acad Sci. 2002;958:163-165.

142. Marttila J, et al. T cell epitopes in coxsackievirus B4 structural proteins concentrate in regions conserved between enteroviruses. Virology. 2002;293(2):217-224.

143. Honeyman MC, Stone NL, Falk BA, Nepom G, Harrison LC. Evidence for molecular mimicry between human $\mathrm{T}$ cell epitopes in rotavirus and pancreatic islet autoantigens. Immunol. 2010;184(4):2204-2210.

144.Cole DK, et al. Hotspot autoimmune T cell receptor binding underlies pathogen and insulin peptide cross-reactivity. JClin Invest. 2016;126(6):2191-2204.

145. Eizirik DL, Miani M, Cardozo AK. Signalling danger: endoplasmic reticulum stress and the unfolded protein response in pancreatic islet inflammation. Diabetologia. 2013;56(2):234-241.

146.Marré ML, James EA, Piganelli JD. $\beta$ Cell ER stress and the implications for immunogenicity in type 1 diabetes. Front Cell Dev Biol. 2015;3:67.

147. Phelps EA, et al. Aberrant accumulation of the diabetes autoantigen GAD65 in Golgi membranes in conditions of ER stress and autoimmunity. Diabetes. 2016;65(9):2686-2699.

148. Cianciaruso $C$, et al. Primary human and rat $\beta$-cells release the intracellular autoantigens GAD65, IA-2, and proinsulin in exosomes together with cytokine-induced enhancers of immunity. Diabetes. 2017;66(2):460-473.

149. Hugues S, et al. Tolerance to islet antigens and prevention from diabetes induced by limited apoptosis of pancreatic beta cells. Immunity. 2002;16(2):169-181.

150. Kurts C, Kosaka H, Carbone FR, Miller JF, Heath WR. Class I-restricted cross-presentation of exogenous self-antigens leads to deletion of autoreactive CD8(+) T cells. JExp Med.1997;186(2):239-245.

151. Belz GT, et al. The CD8alpha(+) dendritic cell is 
responsible for inducing peripheral selftolerance to tissue-associated antigens. J Exp Med. 2002;196(8):1099-1104.

152. Segura E, Amigorena S. Cross-presentation in mouse and human dendritic cells. Adv Immunol. 2015;127:1-31.

153. de Jersey J, et al. Beta cells cannot directly prime diabetogenic $\mathrm{CD} 8 \mathrm{~T}$ cells in nonobese diabetic mice. Proc Natl Acad Sci U S A. 2007;104(4):1295-1300.

154. Yamanouchi J, Verdaguer J, Han B, Amrani A, Serra P, Santamaria P. Cross-priming of diabetogenic $\mathrm{T}$ cells dissociated from CTL-induced shedding of beta cell autoantigens. J Immunol. 2003;171(12):6900-6909.

155. Ferris ST, Carrero JA, Mohan JF, Calderon B, Murphy KM, Unanue ER. A minor subset of Batf3-dependent antigen-presenting cells in islets of Langerhans is essential for the development of autoimmune diabetes. Immunity. 2014;41(4):657-669.

156. Mariño E, Tan B, Binge L, Mackay CR, Grey ST. B-cell cross-presentation of autologous antigen precipitates diabetes. Diabetes. 2012;61(11):2893-2905.

157. Diez J, et al. Differential splicing of the IA-2 mRNA in pancreas and lymphoid organs as a permissive genetic mechanism for autoimmunity against the IA- 2 type 1 diabetes autoantigen. Diabetes. 2001;50(4):895-900.

158. Dogra RS, Vaidyanathan P, Prabakar KR, Marshall KE, Hutton JC, Pugliese A. Alternative splicing of $\mathrm{G} 6 \mathrm{PC} 2$, the gene coding for the isletspecific glucose-6-phosphatase catalytic subunit-related protein (IGRP), results in differential expression in human thymus and spleen compared with pancreas. Diabetologia 2006;49(5):953-957.

159. de Jong VM, et al. Alternative splicing and differential expression of the islet autoantigen IGRP between pancreas and thymus contributes to immunogenicity of pancreatic islets but not diabetogenicity in humans. Diabetologia. 2013;56(12):2651-2658.

160.Doyle HA, Mamula MJ. Autoantigenesis: the evolution of protein modifications in autoimmune disease. Curr Opin Immunol. 2012;24(1):112-118.

161. Ferris ST, Carrero JA, Unanue ER. Antigen presentation events during the initiation of autoimmune diabetes in the NOD mouse. JAutoimmun.
2016;71:19-25.

162. Mohan JF, Petzold SJ, Unanue ER. Register shifting of an insulin peptide-MHC complex allows diabetogenic $\mathrm{T}$ cells to escape thymic deletion. J Exp Med. 2011;208(12):2375-2383.

163. Nguyen $\mathrm{H}$, James EA. Immune recognition of citrullinated epitopes. Immunology. 2016;149(2):131-138.

164.McGinty JW, Chow IT, Greenbaum C, Odegard J, Kwok WW, James EA. Recognition of posttranslationally modified GAD65 epitopes in subjects with type 1 diabetes. Diabetes. 2014;63(9):3033-3040.

165. Nakayama $\mathrm{M}$, et al. Prime role for an insulin epitope in the development of type 1 diabetes in NOD mice. Nature. 2005;435(7039):220-223.

166. Nakayama M, Simmons KM, Michels AW. Molecular interactions governing autoantigen presentation in type 1 diabetes. Curr Diab Rep. 2015;15(12):113.

167. Suri A, Walters JJ, Gross ML, Unanue ER. Natural peptides selected by diabetogenic $\mathrm{DQ} 8$ and murine $\mathrm{I}-\mathrm{A}(\mathrm{g} 7)$ molecules show common sequence specificity. JClin Invest. 2005;115(8):2268-2276.

168. Mohan JF, Calderon B, Anderson MS, Unanue ER. Pathogenic $\mathrm{CD} 4^{+} \mathrm{T}$ cells recognizing an unstable peptide of insulin are directly recruited into islets bypassing local lymph nodes. J Exp Med. 2013;210(11):2403-2414.

169.Crawford F, et al. Specificity and detection of insulin-reactive $\mathrm{CD} 4+\mathrm{T}$ cells in type 1 diabetes in the nonobese diabetic (NOD) mouse. Proc Natl Acad Sci U S A. 2011;108(40):16729-16734.

170. Nakayama M, et al. Regulatory vs. inflammatory cytokine T-cell responses to mutated insulin peptides in healthy and type 1 diabetic subjects. Proc Natl Acad Sci U S A. 2015;112(14):4429-4434.

171. Yang J, et al. Autoreactive $T$ cells specific for insulin B:11-23 recognize a low-affinity peptide register in human subjects with autoimmune diabetes. Proc Natl Acad Sci U S A. 2014;111(41):14840-14845.

172. Schubert DA, et al. Self-reactive human CD4 T cell clones form unusual immunological synapses. J Exp Med. 2012;209(2):335-352.

173. Delong T, et al. Pathogenic CD4 T cells in type 1 diabetes recognize epitopes formed by peptide fusion. Science. 2016;351(6274):711-714.

174. Baker RL, et al. Cutting edge: nonobese diabetic mice deficient in chromogranin $\mathrm{A}$ are protected from autoimmune diabetes. JImmunol. 2016;196(1):39-43.

175. Babon JA, et al. Analysis of self-antigen specificity of islet-infiltrating $T$ cells from human donors with type 1 diabetes. Nat Med. 2016;22(12):1482-1487.

176. Kracht MJ, et al. Autoimmunity against a defective ribosomal insulin gene product in type 1 diabetes. Nat Med.2017;23(4):501-507.

177. Unger WW, et al. Islet-specific CTL cloned from a type 1 diabetes patient cause beta-cell destruction after engraftment into HLA-A2 transgenic NOD/scid/IL2RG null mice. PLoS One. 2012;7(11):e49213.

178. Viehmann Milam AA, et al. A humanized mouse model of autoimmune insulitis. Diabetes. 2014;63(5):1712-1724.

179. Pathiraja V, et al. Proinsulin-specific, HLA-DQ8, and HLA-DQ8-transdimer-restricted CD4+ T cells infiltrate islets in type 1 diabetes. Diabetes. 2015;64(1):172-182.

180. McGinty JW, Marré ML, Bajzik V, Piganelli JD, James EA. T cell epitopes and post-translationally modified epitopes in type 1 diabetes. Curr Diab Rep. 2015;15(11):90.

181. Michels AW, et al. Islet-derived CD4 T cells targeting proinsulin in human autoimmune diabetes. Diabetes. 2017;66(3):722-734.

182. Seay HR, et al. Tissue distribution and clonal diversity of the $\mathrm{T}$ and $\mathrm{B}$ cell repertoire in type 1 diabetes. JCI Insight. 2016;1(20):e88242.

183. Eugster A, et al. High diversity in the TCR repertoire of GAD65 autoantigen-specific human CD4+ T cells. J Immunol. 2015;194(6):2531-2538.

184. Oling V, et al. GAD65- and proinsulin-specific CD4+ T-cells detected by MHC class II tetramers in peripheral blood of type 1 diabetes patients and at-risk subjects. J Autoimmun. 2005;25(3):235-243.

185. Pugliese A, et al. Self-antigen-presenting cells expressing diabetes-associated autoantigens exist in both thymus and peripheral lymphoid organs. JClin Invest. 2001;107(5):555-564.

186. Metzger TC, Anderson MS. Control of central and peripheral tolerance by Aire. Immunol Rev. 2011;241(1):89-103.

187. Fuhlbrigge R, Yip L. Self-antigen expression in the peripheral immune system: roles in selftolerance and type 1 diabetes pathogenesis. Curr Diab Rep. 2014;14(9):525. 